\title{
Thermal stability of CK60 steel nano-Crystallized by drilling method
}

\begin{abstract}
In present study drilling as a new Surface Sever Plastic Deformation technique (SSPD) has been applied to commercial CK60 steel plate to create a nanoCrystalline (NC) structured layer. The CK60 steel plate with tempered martensitic crystalline structure has been drilled using hard titanium coated drilling bit under $20 \mathrm{~m} / \mathrm{min}$ cutting speed. The formed surface nanocrystalline (NC) layers characterized by using field emission scanning electron microscope (FESEM) and microhardness tests. The results showed that the hardness of formed NC layer with almost 50nm grain sizes was more than twice of the martensitic base metal hardness. The thermal stability of NC layer has been studied in the range of 673 to $923 \mathrm{~K}$ and the results showed that created fine grain structure had higher thermal stability compared to CK60 steel samples with coarse granular crystalline structure. The microhardness of NC layers reduced from 9.8 to $9.1 \mathrm{GPa}$ after 1 hour tempering at $923 \mathrm{~K}$.
\end{abstract}

Keyword: CK60 steel; Drilling; Nanocrystallization; Single Source of Product Data (SSPD); Thermal stability 